\title{
TEACHING VERY YOUNG LEARNERS ONLINE: HOW TO KEEP CURIOUS MINDS CURIOUS IN A DIGITAL WORLD
}

\author{
Veliou Elisavet \\ House of English Language School \& Research Centre, Greece
}

\begin{abstract}
Teaching very young learners is one the most challenging, yet, most rewarding things in the field of TEFL. Teaching preschoolers and kindergarten students focuses on teaching the language by creating experiences. However, how feasible can this be at the time of the pandemic when classrooms turned into virtual classrooms and EFL teachers of very young learners had to face a new set of challenges? This paper is about teaching English to very young learners (4-6 years old) online. The paper explores some of the key characteristics, needs and strengths of the very young learners and the challenges of online education with those age groups, and then goes on to examine the practical implications as these relate to our planning and teaching methodologies. Finally, it focuses on how teaching very young learners means exposing students to the target language through messy play, CLIL, Art, storytelling and activities that place the child in the centre of the learning procedure, giving them reasons to use the language and engaging them meaningfully through fun and creative activities, even when lesson takes place online, in a Digital World.
\end{abstract}

Keywords: preschool, education, kindergarten, multisensory, online

\section{Introduction}

Teaching very young learners has always been one of the most challenging things in the field of education. The age of the learners in combination with their short attention span and their profile which will be analysed later on, makes teaching them a demanding task, yet a most rewarding one.

Let's take a look at those very young learners. Who are they? Their age ranges from 3 to 7 years old but there is methodology for teaching 2-year-olds too. Most language schools in Greece have language classes for age groups from 4-5 years old (pre-k groups), 5-6 years old (kindergarten groups) and 6-7 years old (pre-junior groups). For the rest of the essay, I shall call those very young learners VYL.

At the beginning of this essay, we will look at the VYL profile, the methodology we use for teaching those age groups and we will explore how those VYL learn. Then we will examine the practical implications when teaching VYL online and how we can solve some of the problems that may occur. Finally, we will look at the activities a language school can incorporate in its syllabus when teaching VYL online so as to keep them actively engaged in the learning procedure and achieve the learning objectives.

When it comes to very young learners it has been suggested that there is a critical period during which children have the maturity and predisposition to acquire the foreign language. This critical period is at 
puberty for Lenneberg, between 2-5 for Krashen and at 4-5 according to modern researchers like Meier. Long (1990) provides many evidences in his review on second language acquisition as to the necessity of early acquisition. The study reveals that native-like proficiency in phonology is almost unachievable after 6 years old. We can see that cognitive immaturity of children constitutes of an advantage since their cognitive abilities can function as an impediment to second language acquisition. Children of the critical period are excellent imitators of foreign phonemic systems and they can easily overcome any obstacles at a phonetic level. That is why the teacher's pronunciation should be very close of a native speaker's.

According to Piaget's theory of cognitive development, preschoolers are in the preoperational stage of intelligence so learning can be boosted by helping them experience with concrete materials such as objects, pictures, stories, and videos (Morrison, 2003). During the activities there should be given as much input as possible in the target language as well in the form of comments, directions or songs related to the topic of the activity (Diafermou, Koulouri, Mpakogianni 2006)

\section{Methods}

The following research is a type of a narrative inquiry, based on methods and activities the author and his colleagues practiced in their language school. The COVID-19 pandemic has presented some unique challenges for early years educators as they had to move to a remote learning approach. In our language school we started teaching online since the first lockdown in March 2020 with children aged from 4 to 16 years old. We were the only school in the area teaching very young learners online. This year we continue teaching English as a foreign language to students of all ages, including 4 levels of very young learners aged 3 to 7 years old. The activities and my research are based on teaching examples and on the feedback of our Students' parents from our school and two kindergarten schools that we cooperate with as teachers of English.

\section{Results and Discussion}

Moving on, we will look at very young learners' profile which is very important to know in order to base our methodology, especially when teaching online.

Very young learners are kinaesthetic learners which means that they learn while moving around, while being active. They have a very short attention span as well. The average attention span of a 4year-old ranges between 8-20 minutes, for a 5-year-old between 10-25 minutes, for a 6-year-old between 12-30 minutes and for a 7-year-old between 14-35 minutes. Very young learners are naturalistic learners. They love outdoor activities and whatever has to do with the natural world. They are egocentric and easily bored, that is why the teacher has to prepare a lot of activities for the same learning objective. They are less shy than older learners since school has not deprived them of their spontaneity and they are not afraid to make mistakes. They enjoy imitating and are skillful in listening accurately that is why it is important that the teacher is a perfect language model for the students. Moreover, very young learners enjoy learning through playing, acting, making and doing but mostly by exploring and discovering are imaginative. They understand language as units not separate words. They interpret meaning without necessarily understanding the individual word and they learn indirectly rather than directly. Very young learners love praise and reward and should be given positive feedback every time they achieve a goal. Finally, they develop physically, mentally and conceptually every day. That is why the activities differ from level to level and the teacher should 
always pay attention that they are age appropriate. (Ersoz, A., (2007), Teaching English to Young Learners and Rodríguez-Lopez B. and R., Varela-Móndez, (2004) Models of Teaching Foreign Languages to Young Children)

As regards the basic methodology when teaching very young learners online, the focus should always be on Listening and Speaking, same way as in face-to-face lessons. The emphasis should be on the meaning and not on the form for these levels, and this can be achieved through fun, engaging activities that create the need for communication. Authentic material, songs, stories, fairytales, plays, games, movement and interaction are essential to teach VYL online as well as tasks that arouse their curiosity and initiate production (Science Lab and Art Lab). Sole use of L2 in the classroom is essential, same as routines since children of that age feel comfortable and safe knowing what follows.

There is a special kind of language we tend to use with those age groups called "Motherese". You can also find it as parentese, caretaker speech, input language, child- directed speech, baby talk. The teacher uses simple words such as "tummy" for abdomen, "mummy" for mother, "boo-boo" for wound or hurt with a shift in the vocal timbre.

When it comes to commands and classroom language, we use the so called "teacherese", simple commands, with repetitions accompanied by body language.

Demanding but manageable and developmentally appropriate activities should be selected and finally the sessions when it comes to online lessons should be short, since children of that age have a short attention span, but frequent.

In general, VYL learn a foreign language when they are actively involved, use their senses to make sense of the environment, practice role play and share their experiences with others. They should gradually be able to solve problems, practice and refine their skills, and imitate others after observing them. The teacher must be a perfect language model since the students will mainly imitate his pronunciation. Students should be exposed to a wide range of materials and activities, be given lots of examples, lots of repetition and practice and they should be given the time to react to any stimulus so as to be able to respond to it. Last but not least, at an emotional level, VYL must see that someone is interested in what they do or are trying to solve, feel safe and loved and be praised for their effort. (Harmer, J., (2007) The Practice of English language teaching and Gardner-Neblett, N and K. C. Gallagher, (2013), more than baby talk: 10 ways to promote the language and communication skills of infants and toddlers.)

When teaching VYL online there are some practical implications which we cannot oversee. Some of them can be easily overcome with the use of technology and the implementation of special methodology for teaching these levels online, but some of them still remain a problem.

First of all, teachers of VYL are not very familiar with online teaching. It is not something necessary for their job, it has never been essential for their teaching so their knowledge about teaching online is limited. However, due to the fact that they had to adapt to the new circumstances, many teachers have developed their digital skills, attended webinars and studied methodologies and are now able to teach VYL online. Next, teacher's talking time takes more and Student's talking time is limited when teaching online. Instructions cannot easily be given online using solely L2 since you cannot physically guide the learner during the procedure. Online learning makes the students passive learners; however, 
it is up to the teachers to implement creative tasks that engage the students and promote communication. VYL need physical interaction to create attachment with the teacher. That is one of the greatest implications when teaching these levels online. Children of that age need to see the teacher as a mother or father figure to create a bond and build a strong bond with him or her so they will feel safe in order to learn. When lessons start face-to-face and continue online this bond has been created. Nevertheless, in the case that lessons start in the form of online teaching and learning, the teacher has to make a great effort to create this bond while not being physically there. Moreover, the youngest the child, the shortest the attention span, which means that if a lesson lasted for an hour face-to-face, it should last thirty minutes online with more frequent sessions during the week. Finally, pair work and groupwork are not encouraged when teaching online. However, with the use of breakout rooms and the implementation of engaging activities this no longer constitutes a major problem when teaching VYL online.

Storytelling is one of the greatest ways to teach language to VYL. For 3-4-year-old students animal books or text that describes the picture are ideal and for older students, short stories which include visual representation of the action. When teaching online you can have a Power Point presentation of the book or the teacher can narrate the story while showing the pages of the book to the students. In that case, the big book version of the story is needed. Another great way to present a story while teaching online is the storytelling glove. You can see an example of this in the picture bellow.

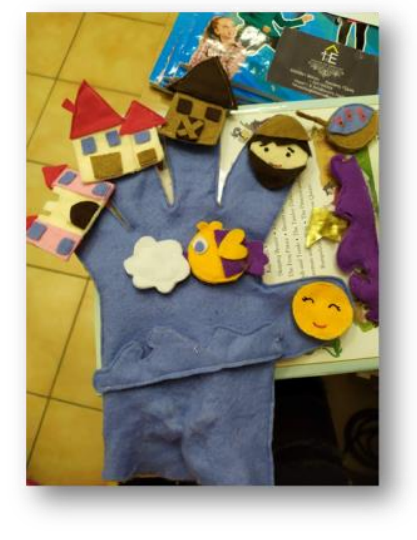

Figure 1: The Fisherman and the Fish

Of course, the implementation of follow-up activities to engage students and check their understanding is essential. Sequencing activities that will check students' understanding can be applied with digital cards. Games with flashcards using webtools such as Quizlet can be used for vocabulary practice for older students and Yes/ No questions as well to check students' comprehension of the story's events. Crafts are another way to engage students after storytelling since you can ask them to create a craft inspired by the story and present it to their classmates. Even cooking lab ideas can be implemented as a follow up activity to storytelling projects. In the picture bellow you can see an activity based on the book "The Snowman", by Raymond Briggs. The teacher had uploaded the material on the asynchronous platform and together with the students they carried out the activity while online. 


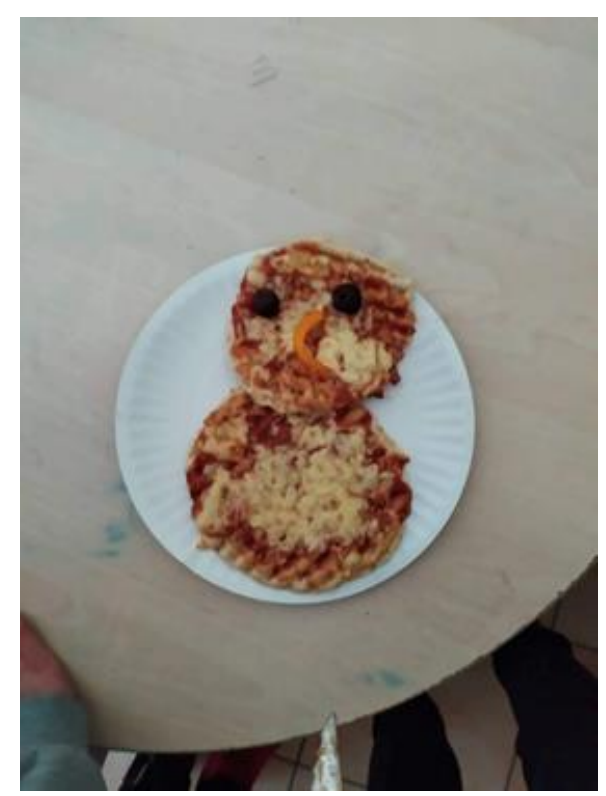

Figure 2: Snowman Pizza

Other follow-up activities involve the use of puppets to retell the story-students may have created finger puppets with the templates which can be uploaded at the asynchronous platform, live worksheets to work on them while online or at their own pace at home, or even the drawing of a story map on a piece of paper and the narration of the story to their classmates while online. Moreover, a great idea is to assign as a kind of "homework" to your students to prepare a story in a bag with materials they will collect from a walk or from things that they have at home and then narrate it to their classmates during their next online session. It is a great multisensory experience that takes the children outside of the house and puts them into the centre of the learning procedure.

Finally, when teaching storytelling online it is crucial to remember that there should be thorough preparation, lots of miming and body language, change at the tone of the voice when needed, slow paced reading and engaging follow-up activities.

Another way to teach language to VYL is through Art. That can be done by making Cultural Tradition Projects, collages, cooking in the classroom projects and recreation of famous paintings. Theory of Art can also be incorporated in the syllabus as well as Performing Arts.

Topic Vocabulary can be taught using authentic material as the pieces of art shown in the pictures bellow to teach for example, shapes \& colours, furniture and family members respectively. 

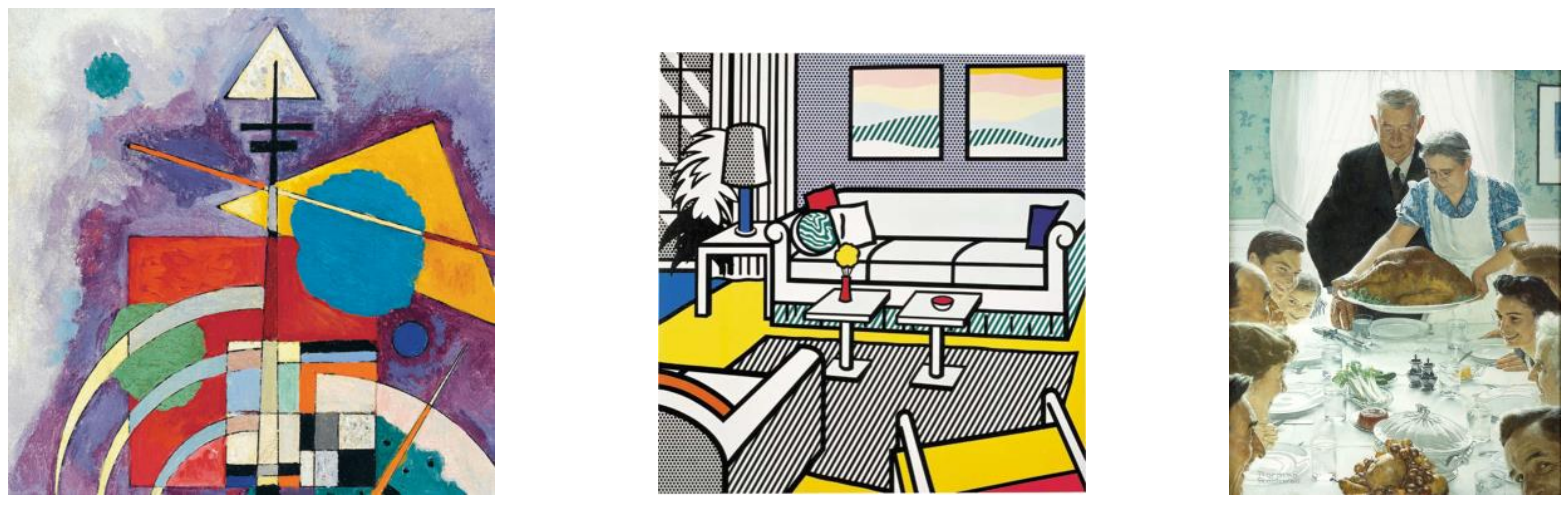

Figures 3, 4, 5 Teaching Topic Vocabulary Through Art

Through Art, children can be also taught arts \& crafts vocabulary (cut, stick, draw, colour, draw lines, match, shape, roll etc), descriptive vocabulary (light, dark, soft, hard, big, small, looks like, round, red etc.), adverbs (softly, loudly, carefully, slowly, up, down, in the middle, to the right, to the left etc.), directions (look, do, firstly, then, you must etc.) and positive feedback vocabulary (nice, excellent, fantastic, wonderful, I think it is...etc.).

When it comes to Performing Arts, some online drama games can be suggested. Simple phrases in a different tone or voice can be performed by the students as a pre-reading or speaking task. The teachers can use music, sound and instruments to present different emotions such as sad, happy, angry or tired and have students act them out. Another idea is to hold an online fashion show to practice clothes vocabulary and present continuous structure experientially. Sensory drama games are also very engaging. The teacher asks students to act out an action pretending to do something like that: eat a lemon, eat ice, touch hot water, touch lava and so on.

Another easily adaptable activity for online lessons, is the creation of a science lab slot. At that time students can explore language while exploring the world. They will use simple materials that they can find at home and with the guidance of their teacher they will carry out simple experiments and learn simple topic vocabulary while gaining valuable knowledge of the world around them. An example of that is the floaters/sinkers experiment. The students will only need a bowl filled with water, two bins to sort the objects into floaters and sinkers and a collection of objects. Students gain an intuitive understanding of density by comparing objects of equal volumes but different masses and at the same time they are actively engaged in the language learning procedure.

Games is another way to keep VYL involved and active during online lessons. There are many kinds of games you can play with your VYL behind the screen. Flashcards Games are very popular since they require no preparation from the part of the teacher and flashcards can be used in many different ways.

"What is missing?" is a popular game which can be easily adapted online. The teacher places the flashcards on the wall or the whiteboard and makes sure that all students can see them. Then, asks students to look at them closely for some seconds. The teacher turns off the camera and removes one flashcard, then turns on the camera and ask students what is missing! 
The same way you can play matching games or you can place the flashcards on the wall or on the whiteboard, turn off the lights and using a torch, light the number, shape, colour or vocabulary item you would like the students to say. This way, you create a classroom-like environment, students feel comfortable and familiar with the learning procedure and they are actively engaged as well.

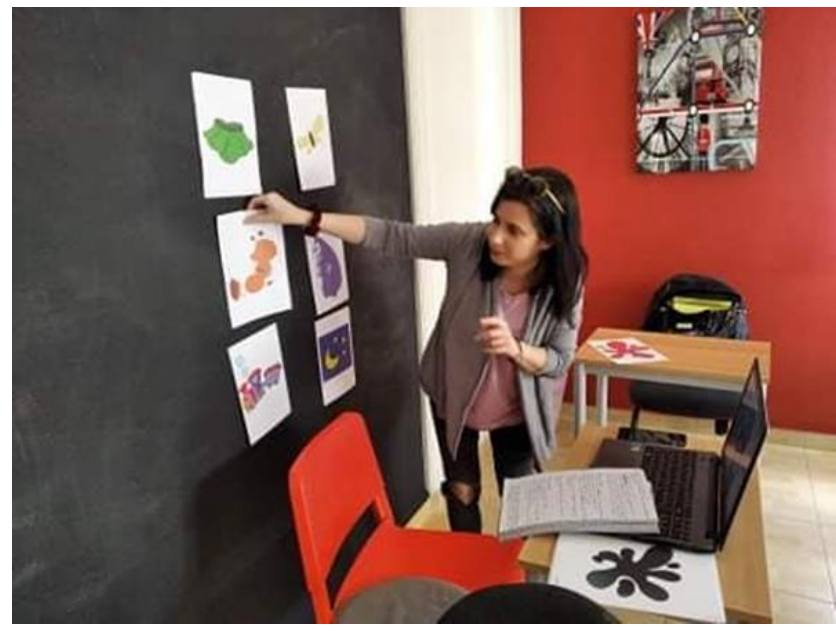

Figure 6. Flashcards Games

Scavenger Hunt Games are also very engaging when teaching VYL online. You can practice all kinds of topic vocabulary and check students' understanding and they are great to have students move around during their online lesson. The teacher asks students to stand up and find things in the house giving them orders like "Find something blue/green/red, open your fridge and find something..., bring me something from your kitchen/bedroom etc., find something that belongs to your mother/father etc."

Whiteboard games are very easy to be played online too. The teacher can start drawing something on the whiteboard asking "What am I drawing?" and the students have to guess what it is before he/she finishes it. This is a great way to keep learners engaged while practicing vocabulary.

Paper dance is also a fun way of learning for young kinaesthetic learners. Students, while at home, take an A4 piece of paper and put it on the floor. The teacher shares audio and plays some music. The students have to dance on the piece of paper and when the music stops, they have to freeze and do what their teacher tells them to do. For example, "touch your nose", "touch your feet" and so on.

\section{Further Research}

In future work, investigating how VYL could work in pairs or groups online might prove important. Although breakout rooms have been commonly used with young learners and teenagers they have not been used greatly when teaching preschoolers or kindergarten students. Since cooperation and collaboration are very important skills which need to be enhanced and developed starting from an early age, further research on this issue is certainly required to disentangle the complexities when teaching very young learners online. 


\section{Conclusion}

As it was clearly stated by Nicky Hockly and Lindsay Clandfield (2010) in their book Teaching Online Tools and techniques, options and opportunities, "Whether you perceive online teaching as an opportunity or as an ordeal will depend to a large extent on how well prepared you are to deal with this new form of teaching and learning". Teaching Very Young Learners is a challenge itself. Teaching them online needs thorough preparation and lots of creativity. You have to have a lot of back up activities for the same learning objective in case something does not work. You should not depend on webtools because VYL are not very familiar with them. You should include activities for all types of learners as you would do in the face-to-face classroom. Finally, you should make them interact with each other and move around, making sure they will not become passive learners. Children of that age group need to be challenged, need to feel safe and need to have fun while learning. This is the final goal and it can be achieved in classrooms or e-classrooms when the teacher is well-prepared and knows the techniques that can make an online lesson an exciting experience.

\section{Acknowledgments}

This paper is an output of the empirical research of the last five years in our English school \& Research Centre. The greatest part of the research was conducted the past two years during the pandemic. So, I would like to express my sincere thanks to the many parents who trusted us and believed in a different Education System, when it comes to teaching English as a foreign language.

My gratitude also goes to my husband, co-teacher and co-owner in our school for being part of my dream of a different, innovative Education and to my team of the past two years who have been working really hard in order to make this dream come true.

Finally, I am very grateful to my students who helped me see through their eyes, made me want to become a better person and a better educator and have always helped me choose "the road not taken" and that has made the difference in my life and theirs as well.

\section{References}

Dafermou. H, Koulouri, P and Mpasagianni, E. (2006) A Guide for Kindergarten Teachers. Educational Designs. Creative Learning Environments. Greek Letters: Athens

Ersoz, A., (2007), Teaching English to Young Learners, Ankara: EDM Publishing

Gardner-Neblett, N and K. C. Gallagher, (2013), More than baby talk: 10 ways to promote the language and communication skills of infants and toddlers, Chapel Hill: The University of North Carolina, FPG child Development Institute, North Carolina, pg. 2

Harmer, J., (2007) The Practice of English language teaching, Essex: Pearson Longman

Hockley, N. with Clandfield, L. (2010), Teaching Online Tools and techniques, options and opportunities, Surrey: Delta Publishing

Krashen, S.D. and T.D Terrell, (1983) The Natural Approach. Language Acquisition in the Classroom, Pargamon, Oxford

Long, M. (1990). Maturational constraints on language development. Studies in Second Language Acquisition, 12, 251-285.

Meier, Richard P.Journal of Child Language; Cambridge Vol. 28, Iss. 1, (Feb 2001): 213-228. DOI: $10.1017 / \mathrm{S} 0305000900234636$ 
Morrison, G. S. (2003). Early childhood education today. 9th edition. Columbus, Ohio: Merrill Publishing Company

Rodríguez-Lopez B. and R. , Varela-Móndez, (2004) Models of Teaching Foreign Languages to Young Children, Didóctica (Lengua y Literatura) vol. 16, 163-175, pgs. 167-168

Vanpatten, B -Keating,G.D- Wulff, S. (2020) Theories in Second language Acquisition: An Introduction, Routledge 